\title{
Investigation of Helium Behavior in Multilayered Hydride Structures Through In- situ TEM Ion Implantation
}

\author{
Caitlin A. Taylor ${ }^{*}$, Khalid Hattar $^{1}$, Bruce Arey ${ }^{2}$, Bethany E Matthews ${ }^{2}$, Dale Zschiesche ${ }^{1}$, Ron Goeke ${ }^{1}$ \\ 1. Sandia National Laboratories, Albuquerque, NM, USA \\ 2. Pacific Northwest National Laboratory, Richland, WA, USA \\ * Corresponding author: ctaylo@sandia.gov
}

Solid-state tritium storage materials are one option for the long-term storage of tritium quantities necessary for the operation of fusion energy programs. In these materials, tritium forms a separate crystalline phase with its host metal atoms. Tritium decay causes rapid ${ }^{3} \mathrm{He}$ build-up in these materials. Helium is insoluble in metals and typically precipitates into bubbles, which cause mechanical property degradation. Once the microstructure becomes saturated with helium bubbles, blisters begin to form, eventually resulting in spallation of the surface. Previous work [1-4] has shown that multilayer interfaces act as trapping sites for helium atoms, preventing helium from diffusing to the surface to form blisters. In this work, helium bubble nucleation and growth were studied in erbium multilayered structures. Unlike many metals (e.g. Ti, $\mathrm{Zr}$ ), erbium readily hydrides into single phase $\mathrm{MH}_{2}$. Erbium deuteride $\left(\mathrm{ErD}_{2}\right)$ was used as a surrogate for erbium tritide $\left(\operatorname{ErT}_{2}\right)$.

Multilayered structures were prepared by first sputter depositing a $\mathrm{Cr}$ adhesion layer onto a single crystal Si substrate at room temperature. Molybdenum is completely immiscible with Er below $1000^{\circ} \mathrm{C}$ and was thus utilized as the secondary metal. A $10 \mathrm{~nm}$ Mo layer was sputter deposited on top of the $\mathrm{Cr}$ layer at room temperature. Subsequent Er and Mo layers were evaporated at $400^{\circ} \mathrm{C}$. In a few samples, the Er layers in the structure were loaded with deuterium to form $\mathrm{ErD}_{2} / \mathrm{Mo}$ multilayers. Formation of the hydride structure was confirmed in these samples using X-ray diffraction (XRD). TEM samples were prepared from $\mathrm{Er} / \mathrm{Mo}$ and $\mathrm{ErD}_{2} / \mathrm{Mo}$ multilayers using a focused-ion beam (FIB). The resulting multilayered structure was confirmed with STEM/EDS, shown for the Er/Mo multilayers in Fig 1. The STEM/EDS showed large grains of erbium oxide $\left(\mathrm{Er}_{2} \mathrm{O}_{3}\right)$ in the Er multilayered structures, and more so in the $\mathrm{ErD}_{2}$ multilayered structures, consistent with the XRD results. In-situ ${ }^{4} \mathrm{He}$ implantation was utilized as an accelerated aging method to simulate the significant ${ }^{3} \mathrm{He}$ accumulation that would occur due to tritium decay in a material. The $\mathrm{I}^{3} \mathrm{TEM}$ at Sandia National Laboratories was used for this work. $10 \mathrm{keV} \mathrm{He}{ }^{+}$ions were accelerated into a JEOL 2100 TEM using a Colutron accelerator. To avoid electron beam interactions with the sample and microscope magnet interactions with the ion beam, the beam was blanked and the microscope objective lens voltages were lowered during implantation. TEM images were taken after fluences of $5 \times 10^{16}, 8 \times 10^{16}$, and $1 \times 10^{17}$ ions $/ \mathrm{cm}^{2}$ were reached. All implantations were done at room temperature.

Helium bubbles approximately 1-3 nm in diameter were observed to nucleate and grow inside the grains, at multilayer interfaces, and at grain boundaries in both $\mathrm{Er} / \mathrm{Mo}$ and $\mathrm{ErD}_{2} / \mathrm{Mo}$ multilayered structures. Bubbles initially formed chains along multilayer and grain boundary interfaces, eventually resulting in crack formation along the interfaces, shown in the $\mathrm{ErD}_{2} / \mathrm{Mo}$ multilayered structure in Fig 2 (a). Inside the grains, bubbles appeared spherical and primarily homogeneously distributed in all layers. This is in contrast to the lenticular bubbles observed in aged $\mathrm{ErT}_{2}$ [5]. Large spherical bubbles were identified near the surface, shown in Fig 2 (b) for the $\mathrm{ErD}_{2} / \mathrm{Mo}$ multilayered structure, and occasionally elsewhere. Fewer bubbles were observed inside the Mo grains than inside the $\mathrm{Er}, \mathrm{ErD}_{2}$, or $\mathrm{Er}_{2} \mathrm{O}_{3}$ grains, likely due to the smaller grain size in the Mo layers. Differences in bubble microstructure between the ErD 2 and $\mathrm{Er}_{2} \mathrm{O}_{3}$ grains were not obvious in this study and are still being investigated. The possible presence of 
denuded zones near interfaces is still be characterized.

These results have provided an initial understanding of how He bubbles form in multilayered hydride structures. Ongoing efforts intend to determine how He bubbles form in pure $\mathrm{ErD}_{2}$, and how the bubble microstructure compares to tritium aged material. Multilayered structures are being $\mathrm{He}$ implanted at several fluences in bulk and will eventually be compared with tritium aged $\operatorname{ErT}_{2} / \mathrm{Mo}$ multilayered samples to see how irradiation damage produced by the helium ion beam is affecting the bubble microstructure, thereby evaluating the use of ion implantation as an accelerating aging method.

References:

[1] Li et al. Philosophical Magazine Letters 91 (2011) 18-28.

[2] Li et al. International Journal of Plasticity 32-33 (2012) 1-16.

[3] Chen et al. Science Advances 3 (2017)

[4] Hochbauer et al. J. Appl. Phys. 98 (2005) 123516.

[5] Snow et al. Journal of Nuclear Materials 253 (2014) 296-306.

[6] This work was performed, in part, at the Center for Integrated Nanotechnologies, an Office of Science User Facility operated for the U.S. Department of Energy (DOE) Office of Science. Sandia National Laboratories is a multi-mission laboratory managed and operated by National Technology and Engineering Solutions of Sandia, LLC, a wholly owned subsidiary of Honeywell International, Inc., for the U.S. Department of Energy's National Nuclear Security Administration under contract DE-NA0003525 .

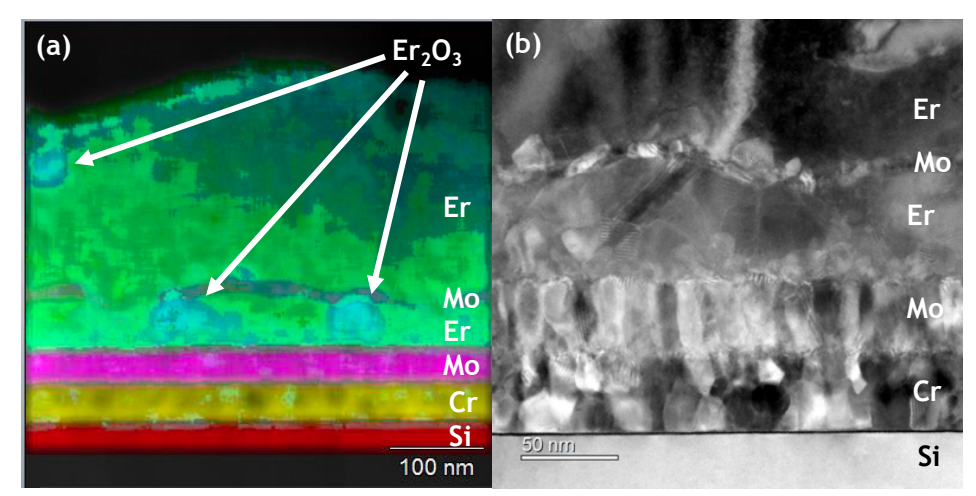

Figure 1. (a) STEM/EDS maps of the Er/Mo multilayers confirming the desired as-deposited multilayer structure. Some Cr diffusion through the initial Mo layer was observed. (b) BF-STEM image showing the granular structure of the multilayers.

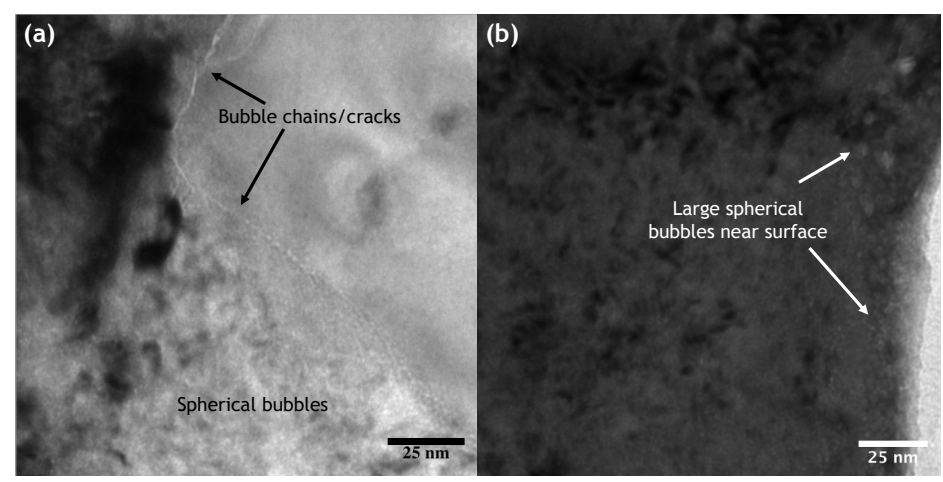

Figure 2. Bright field under-focus TEM images showing (a) bubble chain and crack formation at interfaces and spherical bubbles inside grains, and (b) large spherical bubbles near the surface. 